\title{
Cough augmentation with mechanical insufflation/exsufflation in patients with neuromuscular weakness
}

\author{
M. Chatwin*,\#, E. Ross" ${ }^{\#}$ N. Hart ${ }^{\#}$, A.H. Nickol ${ }^{\#}$, M.I. Polkey*,\#, A.K. Simonds*
}

Cough augmentation with mechanical insufflationlexsufflation in patients with neuromuscular weakness. M. Chatwin, E. Ross, N. Hart, A.H. Nickol, M.I. Polkey, A.K. Simonds. C) ERS Journals Ltd 2003.

ABSTRACT: Adults and children with neuromuscular disease exhibit weak cough and are susceptible to recurrent chest infections, a major cause of morbidity and mortality. Mechanical insufflation/exsufflation may improve cough efficacy by increasing peak cough flow. It was hypothesised that mechanical insufflation/exsufflation would produce a greater increase in peak cough flow than other modes of cough augmentation. The acceptability of these interventions was also compared.

Twenty-two patients aged 10-56 yrs (median 21 yrs) with neuromuscular disease and 19 age-matched controls were studied. Spirometry was performed and respiratory muscle strength measured. Peak cough flow was recorded during maximal unassisted coughs, followed in random order by coughs assisted by physiotherapy, noninvasive ventilation, insufflation and exsufflation, and exsufflation alone. Subjects rated strength of cough, distress and comfort on a visual analogue scale.

In the neuromuscular disease group, mean \pm SD forced expiratory volume in one second was $0.8 \pm 0.6 \mathrm{~L} \cdot \mathrm{s}^{-1}$, forced vital capacity $0.9 \pm 0.8 \mathrm{~L}$, maximum inspiratory pressure $25 \pm 16 \mathrm{cmH}_{2} \mathrm{O}$, maximum expiratory pressure $26 \pm 22 \mathrm{cmH}_{2} \mathrm{O}$ and unassisted peak cough flow $169 \pm 90 \mathrm{~L} \cdot \mathrm{min}^{-1}$. The greatest increase in peak cough flow was observed with mechanical insufflation/exsufflation at $235 \pm 111 \mathrm{~L} \cdot \mathrm{min}^{-1}(\mathbf{p}<0.01)$. All techniques showed similar patient acceptability.

Mechanical insufflation/exsufflation produces a greater increase in peak cough flow than other standard cough augmentation techniques in adults and children with neuromuscular disease.

Eur Respir J 2003; 21: 502-508.
*Sleep and Ventilation Unit and ${ }^{\#}$ Respiratory Muscle Laboratory, Royal Brompton Hospital, London, UK.

Correspondence: M. Chatwin, Sleep and Ventilation Unit, Royal Brompton Hospital, Sydney Street, London, SW3 6NP, UK.

Fax: 442073518911

E-mail: M.Chatwin@rbh.nthames. nhs.uk

Keywords: Noninvasive positive pressure ventilation, paediatrics, physiotherapy, respiratory muscle tests

Received: June 52002

Accepted after revision: October 42002

M. Chatwin was funded by a grant from the Jennifer Trust for Spinal Muscular Atrophy, Stratford-uponAvon, UK. Support for patient expenses was provided by Brompton Breathers Trust Fund, London, UK. E. Ross was funded by the Cystic Fibrosis Trust (Bromley, UK), A.H. Nickol by the British Lung Foundation (London, UK) and N. Hart by the Association Française Contre Les Myopathies (Paris, France).
Effective cough is a protective mechanism against respiratory tract infections, which are the commonest cause of hospital admission in patients with respiratory muscle weakness due to neuromuscular disease (NMD) [1]. These patients may exhibit impaired cough and a reduction in peak cough flow (PCF) as a result of inspiratory and expiratory muscle weakness, which causes a reduction in the pressure available to drive the cough manoeuvre. Bulbar dysfunction producing an inability to rapidly open the glottis and maintain patency of the upper airway during cough may decrease the PCF, even in the presence of normal respiratory muscle function. Although, in most patients with NMD, the degree of inspiratory and expiratory muscle dysfunction is similar [2], in some conditions, such as spinal muscular atrophy, expiratory muscle weakness may be the predominant feature [3].

The current recommendation for airway clearance during chest infections in patients with respiratory muscle weakness is intensive physiotherapy. This consists of a modified active cycle of breathing technique accompanied by physical procedures, such as percussion and shaking, and manually assisted cough [4]. However, intensive physiotherapy is tiring for patients and vigorous physiotherapy can precipitate episodic oxygen desaturation

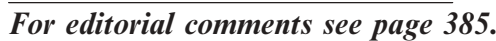

[5]. To improve tolerance, physiotherapy can be combined with assistance from noninvasive positive pressure ventilation (NIPPV) [6], but this approach may still be insufficient to clear secretions adequately, resulting in some patients requiring invasive ventilation.

An alternative approach is mechanical insufflation/exsufflation via a facial mask. The device used has recently received a Conformité Européenne (CE; European conformity) mark, indicating conformity with European Union safety standards, and become widely available in Europe. A mechanical insufflator/exsufflator uses positive pressure to promote maximal lung inflation followed by an abrupt switch to negative pressure to the upper airway. The rapid change from positive to negative pressure is aimed at simulating the flow changes that occur during a cough, thereby assisting sputum clearance. It was hypothesised that mechanical insufflation/exsufflation would increase PCF in patients with NMD. Thus, the aim of the present study was to quantify the magnitude of this effect with mechanical insufflation/exsufflation compared to other cough augmentation techniques commonly recommended for use by the Sleep and Ventilation Unit, Royal Brompton Hospital, London, UK. The aim was also to compare patient (adults and children) tolerance of mechanical insufflation/ exsufflation with that of these other techniques. 


\section{Methods}

\section{Subjects}

The study was approved by the local ethics committee and all subjects and/or their parents gave informed consent. All patients (adults and children) had a history of recurrent chest infections and/or ineffective cough. The aim was to study subjects during a period of clinical stability; therefore, those who had required antibiotic therapy within the preceding month and those with a resting arterial oxygen saturation measured by pulse oximetry $\left(\mathrm{Sp}, \mathrm{O}_{2}\right)$ of $<90 \%$ and/or end-tidal carbon dioxide tension $\left(P \mathrm{ET}, \mathrm{CO}_{2}\right)$ of $>7 \mathrm{kPa}$ were excluded. Additional exclusion criteria were the presence of severe bulbar dysfunction and a previous history of pneumothorax. Agematched controls were recruited from staff and their families.

\section{Measurements}

Sniff nasal inspiratory pressure (SNIP) [7, 8], maximal static inspiratory $(P \mathrm{I}, \max )$ and expiratory $(P \mathrm{E}, \max )$ mouth pressure [9], and maximal whistle mouth pressure $(P$ mo,W $)[10]$ were used as noninvasive indices of inspiratory and expiratory muscle strength. During recording of respiratory muscle strength, subjects were seated comfortably in front of a computer monitor, allowing visual feedback during each manoeuvre. Maximal sniff manoeuvres were performed from functional residual capacity with the subject seated comfortably without a noseclip [7]. Pressures were measured at the nose via a pressure line inserted into a bung. Repeated sniffs were performed until no further increase in pressure was seen, with the highest value being recorded as the SNIP [11]. PI,max was measured during a maximal inspiratory manoeuvre from residual volume via a mouthpiece with a noseclip in situ, performed against a closed shutter [12]. PE,max was recorded using the same equipment during a maximal expiratory manoeuvre from total lung capacity (TLC). Pmo,W was measured during a maximal expiration of $<500 \mathrm{~ms}$ from TLC through a reversed paediatric inhaler whistle (Turbohaler trainer; Astra Pharmaceuticals Ltd, Kings Langley, UK) connected to a flange mouthpiece, without a noseclip [10]. Manoeuvres were repeated at least six times until three readings were within $10 \%$ of each other. The highest of these readings was recorded. All signals were measured using a differential pressure transducer (Validyne, CA, USA) and amplified. The signals passed via an analogue/digital board to a computer running Labview software (National Instruments, Austin, TX, USA). During testing, subjects received strong verbal encouragement [13]. Forced expiratory volume in one second and forced vital capacity were measured using a handheld spirometer (2120; Vitalograph Ltd, Maids Moreton, UK) [14]. Resting $\mathrm{Sp}, \mathrm{O}_{2}$ was recorded using a fingertip probe and portable pulse oximeter (NPB-40; Nellcor, Pleasanton, CA, USA). $\mathrm{Sp}, \mathrm{O}_{2}$ was taken as the highest recorded value measured during a 3-5-min period with the subjects seated in the upright position. $P$ ET, $\mathrm{CO}_{2}$ was recorded while subjects breathed through a full face mask connected via a rigid catheter to a capnograph (PK Morgan, Gillingham, UK), with the baseline reading taken as the $P$ ET, $\mathrm{CO}_{2}$ at the end of $5 \mathrm{~min}$ of resting breathing.

The primary outcome measures of PCF and patient comfort were evaluated during each test procedure. PCF was measured by coughing into a tight-fitting full face mask (Mirage Full-face mask; Resmed, Abingdon, UK) connected via plastic tubing to a metal tube (41 cm long; $3.5 \mathrm{~cm}$ internal diameter). The tube was connected to a Fleisch No. 4 pneumotachograph head (Fleisch, Lausanne, Switzerland) and an electrospirometer (GM Instruments, Kilwinning, UK). The pneumotachograph head was connected via ventilator tubing to a mechanical insufflator/ exsufflator ("Cough-Assist"; JH Emerson Co., Cambridge, MA, USA). Mask pressure was measured from a side port. A technician secured the mask on to the subject's face to minimise air leak.

The comfort of and distress caused by the intervention together with perceived strength of cough were evaluated using a Visual Analogue Scale (VAS) [15]. Following each intervention, the subjects rated comfort of intervention, distress and strength of cough produced (0: least; 10: most).

\section{Cough interventions}

All subjects were studied in their preferred position, usually seated. Initial assessment consisted of at least six maximal unaided coughs followed in random order by the cough intervention techniques; at least six maximal efforts were made during each intervention, with rest periods between them. The cough intervention techniques were: standard physiotherapyassisted cough [4, 16]; cough after inspiration supported by a noninvasive positive pressure ventilator (BiPAP (bilevel positive airway pressure) from Respironics, Inc., Murrysville, PA, USA, or PV401 from Breas Medical, Moinlycke, Sweden) [17]; exsufflation-assisted cough with delivery of negative pressure initiated manually at the end of inspiration; insufflation (given manually during inspiratory phase); and exsufflation-assisted cough with delivery of the negative pressure immediately preceding the cough effort. Use of pressure-limited or preset ventilators meant that patients were unable to "breath stack", with multiple inspirations prior to coughing, as would be possible with volume preset ventilators. Both insufflatory and exsufflatory pressures were titrated to patient comfort.

\section{Statistical analysis}

All values are expressed as mean \pm SD unless stated otherwise. A p-value of $\leqslant 0.05$ was considered significant. Differences in PCF from baseline using different cough-enhancing techniques were analysed using analysis of variance with analysis of significant differences using Tukey's multiple comparison test. Differences in respiratory muscle strength between patient and control groups were compared using a Mann-Whitney U-test as the data were not normally distributed. Spearman's rank correlation coefficient was used to examine the relationship between PCF and inspiratory and expiratory respiratory muscle strength.

\section{Results}

Twenty-two patients (six female) and 19 age-matched controls were studied. Their diagnoses were intermediate spinal muscular atrophy $(\mathrm{n}=10)$, Duchenne's muscular dystrophy $(n=6)$, poliomyelitis $(n=3)$ and other congenital muscular dystrophies $(n=3)$.

Seventeen of the 22 patients were using nocturnal NIPPV at the time of the study (mean duration of ventilation $49 \pm 28$ months). Patients had required between two and six courses of antibiotics during the preceding 12 months for respiratory tract infections and all reported poor cough. Eleven of them had severe scoliosis requiring a spinal jacket (Cobb angle of $>40^{\circ}$ ) and 11 had undergone previous spinal surgery.

Inspiratory and expiratory muscle strength, spirometry, pulse oximetry and $P$ ET, $\mathrm{CO}_{2}$ data are shown in table 1 for the patient group and table 2 for the control group.

For all tests of inspiratory and expiratory muscle function, there was a significant difference between patients and controls 
Table 1. - Patient demographics

\begin{tabular}{|c|c|c|c|c|c|c|c|c|c|c|c|}
\hline $\begin{array}{l}\text { Patient } \\
\text { no. }\end{array}$ & $\begin{array}{l}\text { Age } \\
\text { yrs }\end{array}$ & Diagnosis & $\begin{array}{c}\text { SNIP } \\
\mathrm{cmH}_{2} \mathrm{O}\end{array}$ & $\begin{array}{c}P \mathrm{mo}, \mathrm{W} \\
\mathrm{cmH}_{2} \mathrm{O}\end{array}$ & $\begin{array}{c}P \mathrm{I}, \max \\
\mathrm{cmH}_{2} \mathrm{O}\end{array}$ & $\begin{array}{l}P \text { E,max } \\
\mathrm{cmH}_{2} \mathrm{O}\end{array}$ & $\begin{array}{c}\text { FEV1 } \\
\text { L }\end{array}$ & $\begin{array}{c}\text { FVC } \\
\text { L }\end{array}$ & $\underset{\%}{\mathrm{FEV} 1 / \mathrm{FVC}}$ & $\underset{\%}{S \mathrm{p}, \mathrm{O}_{2}}$ & $\begin{array}{c}P \mathrm{ET}, \mathrm{CO}_{2} \\
\mathrm{kPa}\end{array}$ \\
\hline \multicolumn{12}{|l|}{ Paediatric } \\
\hline 1 & 10 & SMA & 38.0 & 40.0 & 53.2 & 41.7 & 1.5 & 1.7 & 88.4 & 98 & 5.5 \\
\hline 2 & 11 & SMA & 27.2 & 25.7 & 23.7 & 30.6 & 0.4 & 0.4 & 100.0 & 95 & 5.1 \\
\hline 3 & 12 & SMA & 35.7 & 15.0 & & & 0.2 & 0.4 & 50.0 & 97 & 5.9 \\
\hline 4 & 14 & DMD & 21.0 & 19.0 & 19.0 & 16.7 & 0.4 & 0.5 & 73.6 & 97 & 5.7 \\
\hline 5 & 17 & DMD & 10.0 & 11.2 & 14.5 & 9.7 & 0.4 & 0.5 & 72.9 & 96 & 4.9 \\
\hline 6 & 15 & DMD & 18.0 & 14.6 & 13.6 & 15.4 & 0.4 & 0.9 & 44.0 & 97 & 6.1 \\
\hline 7 & 14 & CMD & 29.8 & 15.1 & 11.6 & 7.8 & $\mathrm{U}$ & $\mathrm{U}$ & & 95 & 5.3 \\
\hline 8 & 16 & CMD & 19.0 & 31.7 & 23.2 & 15.9 & 0.4 & 0.3 & 106.1 & 94 & 6.0 \\
\hline Mean \pm SD & $14 \pm 2$ & & $24.8 \pm 9.5$ & $21.5 \pm 10.0$ & $22.7 \pm 14.3$ & $19.7 \pm 12.2$ & $0.5 \pm 0.4$ & $0.7 \pm 0.5$ & $76.41 \pm 23.63$ & $96 \pm 1$ & $5.6 \pm 0.4$ \\
\hline \multicolumn{12}{|l|}{ Adult } \\
\hline 9 & 18 & SMA & 51.1 & 18.8 & 34.6 & 21.1 & 1.1 & 1.2 & 97.4 & 97 & 5.0 \\
\hline 10 & 18 & DMD & 6.8 & 6.8 & 7.5 & 8.1 & 0.3 & 0.3 & 93.5 & 94 & htvf \\
\hline 11 & 44 & SMA & 28.1 & 55.0 & 30.8 & 61.9 & 2.7 & 3.3 & 81.9 & 97 & 6.0 \\
\hline 12 & 22 & SMA & 30.6 & 37.8 & 63.0 & 31.5 & 1.6 & 2.0 & 76.7 & 97 & 5.6 \\
\hline 13 & 20 & SMA & 13.3 & 11.5 & 12.6 & 11.9 & $\mathrm{U}$ & $\mathrm{U}$ & & 94 & 6.1 \\
\hline 14 & 28 & SMA & 30.1 & 16.9 & 33.3 & 17.8 & 0.9 & 0.9 & 98.8 & 97 & 5.7 \\
\hline 15 & 35 & SMA & 63.5 & 20.9 & 46.8 & 23.5 & 1.3 & 1.4 & 97.1 & 98 & 5.0 \\
\hline 16 & 22 & SMA & 14.2 & 11.0 & 15.5 & 14.8 & 0.3 & 0.4 & 62.8 & 98 & 4.8 \\
\hline 17 & 25 & DMD & 6.4 & 4.6 & 6.9 & 5.4 & 0.3 & 0.5 & 58.3 & 96 & 7.7 \\
\hline 18 & 30 & DMD & 5.0 & 4.4 & 8.9 & 4.6 & $\mathrm{U}$ & $\mathrm{U}$ & & 98 & 7.1 \\
\hline 19 & 22 & CMD & 14.6 & 20.0 & 18.3 & 23.2 & 0.3 & 0.4 & 94.4 & 94 & 5.0 \\
\hline 20 & 56 & Polio & 36.6 & 65.0 & 36.3 & 52.7 & 0.6 & 0.9 & 70.3 & 94 & 5.2 \\
\hline 21 & 53 & Polio & 28.0 & 53.0 & 17.5 & 47.8 & 0.9 & 1.0 & 86.4 & 96 & 5.6 \\
\hline 22 & 45 & Polio & 45.0 & 111.5 & 40.5 & 94.8 & 0.7 & 0.9 & 81.3 & 96 & 5.2 \\
\hline Mean \pm SD & $31 \pm 13$ & & $26.7 \pm 17.9$ & $31.2 \pm 30.5$ & $26.6 \pm 16.8$ & $29.9 \pm 25.8$ & $0.9 \pm 0.7$ & $1.1 \pm 0.9$ & $83.3 \pm 13.9$ & $96 \pm 2$ & $5.7 \pm 0.9$ \\
\hline \multicolumn{12}{|l|}{ All patients } \\
\hline Mean \pm SD & $25 \pm 13$ & & $26.0 \pm 14.8$ & $27.7 \pm 24.6$ & $25.3 \pm 15.4$ & $26.5 \pm 21.9$ & $0.8 \pm 0.6$ & $0.9 \pm 0.7$ & $80.7 \pm 17.3$ & $96 \pm 1$ & $5.6 \pm 0.7$ \\
\hline
\end{tabular}

SNIP: sniff nasal inspiratory pressure; $P$ mo,W: whistle mouth pressure; $P \mathrm{I}$ max: maximal static inspiratory mouth pressure; $P$ E,max:

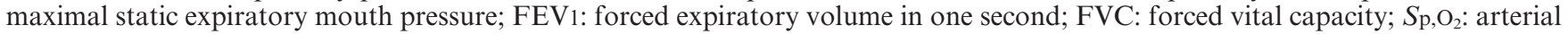
oxygen saturation measured by pulse oximetry; $P \mathrm{ET}, \mathrm{CO}_{2}$ : end-tidal carbon dioxide tension; SMA: spinal muscular atrophy; DMD: Duchenne's muscular dystrophy; CMD: congenital muscular dystrophy; polio: poliomyelitis; U: unrecordable.

$(\mathrm{p}<0.001)$. Compared to controls, expiratory muscle strength was lower in both NMD children (mean differences: $P$ E, max $74 \mathrm{cmH}_{2} \mathrm{O}, P$ mo,W $91 \mathrm{cmH}_{2} \mathrm{O} ; \mathrm{p}<0.001$ ) and adults (mean differences: $P$ E, max $100 \mathrm{cmH}_{2} \mathrm{O}, P$ mo, $\left.\mathrm{W} 128 \mathrm{cmH}_{2} \mathrm{O}, \mathrm{p}<0.001\right)$, indicating severe expiratory muscle weakness. There was no difference in inspiratory and expiratory muscle strength measurements between the different patient groups $(\mathrm{p}=0.89)$.

Resting $\mathrm{Sp}, \mathrm{O}_{2}$ was significantly lower in the patient group than in the control group $(\mathrm{p}<0.005)$. There was no significant difference between $\mathrm{PET}, \mathrm{CO}_{2}$ for the patient and control groups $(\mathrm{p}=0.06)$.

The mask pressure for the patient group was $15 \pm 3 \mathrm{cmH}_{2} \mathrm{O}$ during insufflation and $-15 \pm 9 \mathrm{cmH}_{2} \mathrm{O}$ during exsufflation. For the control group, mask pressure during insufflation was $17 \pm 5 \mathrm{cmH}_{2} \mathrm{O}$ and $-8 \pm 11 \mathrm{cmH}_{2} \mathrm{O}$ during exsufflation.

In the control group, there was a significant positive correlation between PCF and Pmo,W $(\mathrm{r}=0.71 ; \mathrm{p}<0.001)$ and between PCF and $P$ E, $\max (\mathrm{r}=0.67 ; \mathrm{p}<0.002)$. In the NMD group, there was also a significant positive correlation between PCF and Pmo,W $(\mathrm{r}=0.69 ; \mathrm{p}<0.001)$ and between PCF and $P$ E, max $(\mathrm{r}=0.55 ; \mathrm{p}<0.02)$. $P$ E, $\max$ and $P$ mo, W were better correlated in the NMD group $(\mathrm{r}=0.93 ; \mathrm{p}<0.0002)$ than in the control group $(\mathrm{r}=0.85 ; \mathrm{p}<0.0005)$.

Representative flow traces for each of the interventions are shown in figure 1. PCFs for the NMD patients for each intervention (mean $(95 \%$ confidence interval (CI)) were: unassisted cough 169 (129-209) $\mathrm{L} \cdot \mathrm{min}^{-1}$; physiotherapy-assisted cough $188(146-229) \mathrm{L} \cdot \mathrm{min}^{-1}$; noninvasive ventilator-assisted cough $182(147-217) \mathrm{L} \cdot \mathrm{min}^{-1}$; exsufflation-assisted cough 235 (186-284) $\mathrm{L} \cdot \mathrm{min}^{-1}$; and insufflation/exsufflation-assisted cough 297 (246-350) $\mathrm{L} \cdot \mathrm{min}^{-1}$. By comparison, the results for the control group were: unassisted cough $578(508-648) \mathrm{L} \cdot \mathrm{min}^{-1}$; physiotherapy-assisted cough 587 (512-663) L.min ${ }^{-1}$; noninvasive ventilator-assisted cough $565(495-635) \mathrm{L} \cdot \mathrm{min}^{-1}$; exsufflation-assisted cough $633(570-695) \mathrm{L} \cdot \mathrm{min}^{-1}$; and insufflation/ exsufflation-assisted cough $629(565-603) \mathrm{L} \cdot \mathrm{min}^{-1}$. Analysis of variance for interventions revealed significant differences in all groups: patient group $\mathrm{p}=0.001$; control group $\mathrm{p}=0.0001$. There was an increase in PCF from baseline (unassisted cough) with exsufflation $(p<0.001)$ and insufflation/exsufflation $(p<0.01)$ in the control group. In the combined adult and paediatric patient group, an increase in PCF with insufflation/exsufflation was observed compared to exsufflation alone $(p<0.001)$. In addition, in the adult NMD patients, analysis of variance for interventions revealed significant differences $(\mathrm{p}=0.0001)$. There was a difference from baseline PCF with exsufflation $(p<0.01)$, and insufflation/exsufflation $(\mathrm{p}<0.001)$ (fig. 2). The analysis of variance for interventions in paediatric NMD patients revealed significant differences $(\mathrm{p}=0.0001)$. A significant increase in PCF during mechanical insufflation/exsufflation $(\mathrm{p}<0.001)$ was also observed. Analysis of variance for interventions revealed significant differences $(\mathrm{p}=0.0005)$ in the paediatric control group and an increase in PCF during mechanical insufflation/ exsufflation ( $p<0.01)$ (fig. 2). Analysis of variance for interventions revealed significant differences $(p=0.0001)$ for the adult control group. Both patients and controls tolerated all of the interventions well and no adverse events were observed. All subjects, in both the patient and control groups, reported the greatest increase in cough strength compared to unassisted cough during insufflation/exsufflation $(\mathrm{p}<0.001)$. Analysis of variance for interventions revealed significant differences $(\mathrm{p}=0.0001)$ in mean scores. The VAS results (mean $(95 \% \mathrm{CI})$ ) 
Table 2. - Control demographics

\begin{tabular}{|c|c|c|c|c|c|c|c|c|c|c|}
\hline $\begin{array}{l}\text { Patient } \\
\text { no. }\end{array}$ & $\begin{array}{l}\text { Age } \\
\text { yrs }\end{array}$ & $\begin{array}{c}\text { SNIP } \\
\mathrm{cmH}_{2} \mathrm{O}\end{array}$ & $\begin{array}{c}P \mathrm{mo}, \mathrm{W} \\
\mathrm{cmH}_{2} \mathrm{O}\end{array}$ & $\begin{array}{c}P \mathrm{I}, \max \\
\mathrm{cmH}_{2} \mathrm{O}\end{array}$ & $\begin{array}{l}P \text { E,max } \\
\mathrm{cmH}_{2} \mathrm{O}\end{array}$ & $\begin{array}{c}\text { FEV1 } \\
\text { L }\end{array}$ & $\begin{array}{c}\text { FVC } \\
\text { L }\end{array}$ & $\begin{array}{c}\mathrm{FEV} 1 / \mathrm{FVC} \\
\%\end{array}$ & $\underset{\%}{S \mathrm{p}, \mathrm{O}_{2}}$ & $\begin{array}{c}P \mathrm{ET}, \mathrm{CO}_{2} \\
\mathrm{kPa}\end{array}$ \\
\hline \multicolumn{11}{|l|}{ Paediatric } \\
\hline 1 & 11 & 65.4 & 58.3 & 59.7 & 31.0 & 1.4 & 1.8 & 78.4 & 96 & 5.7 \\
\hline 2 & 10 & 90.3 & 100.6 & 89.0 & 112.0 & 1.5 & 2.0 & 73.0 & 96 & 5.1 \\
\hline 3 & 14 & 90.0 & 132.0 & 90.6 & 74.7 & 5.1 & 6.0 & 83.9 & 97 & 5.3 \\
\hline 4 & 12 & 105.6 & 102.5 & 77.7 & 78.0 & 2.6 & 3.3 & 78.5 & 98 & 5.0 \\
\hline 5 & 14 & 103.2 & 70.0 & 91.3 & 90.1 & 2.1 & 2.8 & 73.0 & 98 & 4.6 \\
\hline 6 & 16 & 79.0 & 105.0 & 125.4 & 79.1 & 3.4 & 3.6 & 93.3 & 97 & 5.1 \\
\hline 7 & 15 & 104.0 & 167.7 & 164.8 & 123.8 & 4.5 & 6.2 & 72.2 & 98 & 5.3 \\
\hline 8 & 17 & 129.0 & 170.0 & 120.0 & 164.2 & 2.3 & 2.7 & 86.8 & 97 & 6.1 \\
\hline Mean $\pm S D$ & $13.6 \pm 2.4$ & $95.8 \pm 19.2$ & $113.3 \pm 41.0$ & $102.3 \pm 33.0$ & $94.1 \pm 39.6$ & $2.8 \pm 1.3$ & $3.5 \pm 1.7$ & $79.9 \pm 7.6$ & $97 \pm 1$ & $5.3 \pm 0.4$ \\
\hline \multicolumn{11}{|l|}{ Adult } \\
\hline 9 & 18 & 108.0 & 136.0 & 120.5 & 136.0 & 2.1 & 2.5 & 85.7 & 98 & 5.3 \\
\hline 10 & 25 & 101.0 & 154.2 & 90.9 & 120.6 & 3.8 & 4.5 & 84.0 & 98 & \\
\hline 11 & 44 & 116.0 & 151.0 & 98.6 & 108.6 & 3.0 & 4.7 & 65.4 & 96 & 5.2 \\
\hline 12 & 22 & 130.0 & 208.0 & 149.8 & 157.2 & 4.9 & 6.0 & 69.8 & 98 & \\
\hline 13 & 22 & 67.0 & 95.0 & 48.3 & 85.5 & 3.3 & 3.8 & 88.3 & 99 & 4.8 \\
\hline 14 & 20 & 118.6 & 256.0 & 116.0 & 181.0 & 4.2 & 5.9 & 70.9 & 98 & 5.7 \\
\hline 15 & 18 & 95.0 & 114.0 & 86.1 & 83.9 & 3.4 & 3.7 & 91.8 & 99 & 4.5 \\
\hline 16 & 30 & 114.5 & 152.6 & 161.7 & 177.5 & 3.8 & 4.0 & 77.3 & 98 & 4.0 \\
\hline 17 & 28 & 43.8 & 147.2 & 112.6 & 125.3 & 3.5 & 4.2 & 83.2 & 98 & \\
\hline 18 & 35 & 56.1 & 78.5 & 72.1 & 64.2 & 3.4 & 4.3 & 79.1 & 97 & 5.8 \\
\hline 19 & 22 & 65.2 & 104.5 & 81.8 & 92.4 & 3.2 & 3.4 & 93.6 & 98 & 4.5 \\
\hline Mean \pm SD & $26 \pm 8$ & $92.3 \pm 29.2$ & $145.2 \pm 51.1$ & $103.5 \pm 33.2$ & $121.1 \pm 39.0$ & $3.5 \pm 0.7$ & $4.4 \pm 1.2$ & $80.8 \pm 9.2$ & $98 \pm 1$ & $5.1 \pm 0.5$ \\
\hline Mean \pm SD & $21 \pm 9$ & $93.8 \pm 24.9$ & $131.7 \pm 48.6$ & $103.0 \pm 32.2$ & $109.7 \pm 40.5$ & $3.2 \pm 1.0$ & $4.0 \pm 1.5$ & $80.4 \pm 8.4$ & $98 \pm 1$ & $5.2 \pm 0.5$ \\
\hline
\end{tabular}

SNIP: sniff nasal inspiratory pressure; $P$ mo,W: whistle mouth pressure; $P \mathrm{I}$,max: maximal static inspiratory mouth pressure; $P$ E,max: maximal static expiratory mouth pressure; FEV1: forced expiratory volume in one second; FVC: forced vital capacity; $S_{\mathrm{p}}, \mathrm{O}_{2}$ : arterial oxygen saturation measured by pulse oximetry; $P \mathrm{ET}, \mathrm{CO}_{2}$ : end-tidal carbon dioxide tension.

from the NMD patients were: unassisted cough 5.4 (4.5-6.3) $\mathrm{cm}$; physiotherapy-assisted cough $5.9(5.2-6.7) \mathrm{cm}$; noninvasive ventilator-assisted cough $5.8(4.8-6.8) \mathrm{cm}$; exsufflation-assisted cough $6.9(5.3-7.0) \mathrm{cm}$; and insufflation/exsufflation-assisted cough $7.3(6.6-8.0) \mathrm{cm}$. Control subjects' VAS results were: unassisted cough $7.0(6.4-7.7) \mathrm{cm}$; physiotherapy-assisted cough $7.7(7.1-8.3) \mathrm{cm}$; noninvasive ventilator-assisted cough 7.2 (6.5-7.9) cm; exsufflation-assisted cough $7.9(7.3-8.5) \mathrm{cm}$; and insufflation/exsufflation-assisted cough $8.1(7.5-8.6) \mathrm{cm}$. There was no significant change from baseline in results for comfort or distress of intervention on the VAS.

\section{Discussion}

The main finding of the present study is that, in patients (adults and children) with severe respiratory muscle weakness due to NMD, the combination of insufflation and exsufflation produces a higher PCF than a voluntary unassisted cough or a cough assisted by noninvasive ventilation. Furthermore, mechanical insufflation/exsufflation was tolerated as well as the other techniques of cough enhancement.

\section{Limitations of the study}

The patient group was highly selected in that it showed evidence of extreme muscle weakness, to the extent that the majority $(77 \%)$ of the group used domiciliary NIPPV. Thus, the present data cannot be used to support the use of mechanical insufflation/exsufflation in patients with less advanced disease. However, the observation that mechanical insufflation/ exsufflation confers an advantage over NIPPV-assisted or physiotherapy-assisted cough is particularly impressive given that the majority of the present patients were experienced ventilator users. In addition, patients with severe bulbar dysfunction were excluded, primarily because of the difficulty in interpreting reduced PCF in this group.

The patients were clinically stable and different results might be obtained in patients who are acutely unwell. Previous work suggests that respiratory tract infections can cause a reduction in expiratory muscle strength [18], in which case mechanical insufflation/exsufflation and/or the other techniques applied might confer even greater benefit. In addition, NIPPV-assisted physiotherapy may be helpful in patients with respiratory failure as a consequence of chest infection.

When mechanical insufflation/exsufflation is used in clinical practice, it has been stated that pressures of $-40-40 \mathrm{cmH}_{2} \mathrm{O}$ are necessary for clinical efficacy $[19,20]$. The pressures delivered via the insufflator/exsufflator in the present study, measured at the facemask, were lower than this. "Cough assist" was used in line with the manufacturer's recommendations in a study group who were unfamiliar with this device. However, in spite of the relatively modest pressures applied in the present study, it was still possible to demonstrate a significant increase in peak cough flow. This study was designed to achieve a physiologically significant result, rather than to study the clinical effects of varying forms of cough augmentation. Identification of the optimal clinical pressures required to enhance cough is a subject for future prospective clinical study.

Barometric (pressure preset) ventilators were used in preference to volume preset ventilators, which may increase augmentation of tidal volume [21], because it was felt preferable to use a ventilator that the individual was familiar with, and pressure preset models are the machines most widely available in the UK.

The position in which physiotherapy was performed was not standardised. It was ensured that patients were studied in the most comfortable position; this meant only two were supine. The authors simulated their own clinical practice in that airway 

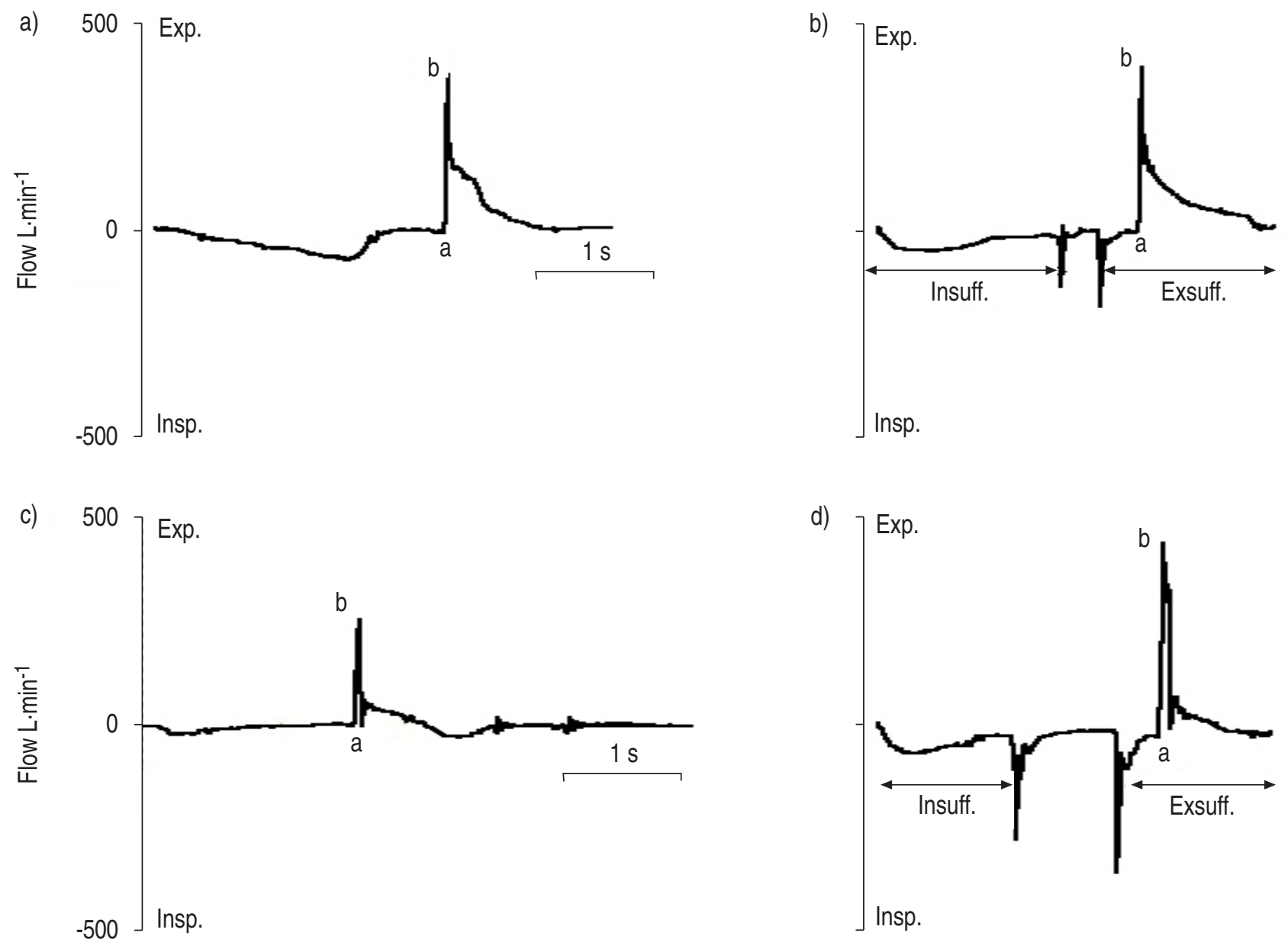

Fig. 1. - a, c) Maximal unassisted cough and b, d) insufflation/exsufflation cough in a, b) a control and c, d) a child with neuromuscular disease. a) represents the start of the cough and b) peak cough flow. The two downward spikes are flow artefact. Note the poor inspiration by the paediatric patient (c). Exp.: expiration; Insp.: inspiration; Insuff.: insufflation; Exsuff.: exsufflation.

clearance techniques were performed in the patient's preferred body position, which encouraged maximal patient cooperation. However, it is acknowledged both that posture influences expiratory flow mechanics directly [22] and some techniques, for example manually assisted cough, may be more effectively applied in the supine position.

\section{Significance of the findings}

It is of interest that $P$ mo, W correlated more closely with PCF than $P$ E,max. This observation is consistent with a previous study in adults with amyotrophic lateral sclerosis in which $P$ E,max was a poor predictor of the ability to generate transient supramaximal flow [2]. It has been hypothesised previously that $P$ E,max may be a poor screening tool as patients find it hard to generate an airtight seal around the mouthpiece. Observations from the current study suggest that subjects found Pmo,W manoeuvres easier to perform. No correlation was found between SNIP and $P$ ET, $\mathrm{CO}_{2}$ but this may be due to the fact that most of the present patients were receiving long-term nocturnal NIPPV, which might influence daytime arterial carbon dioxide tension.

A cough gastric pressure threshold $\left(50 \mathrm{cmH}_{2} \mathrm{O}\right)$, which it is necessary to exceed to generate transient supramaximal flow, has previously been identified [22]. Although cough gastric pressure was not directly measured in the present study, a relationship between cough gastric pressure and $P$ mo, $\mathrm{W}$ has been recently demonstrated [10], and, on this basis, it would be expected that all but two of the present patients would have been unable to produce transient supramaximal flow during an unassisted cough. It is acknowledged that the best cough assist technique for the individual may be dependent on the degree and distribution of respiratory muscle weakness, as well as other factors, including the presence of irreversible expiratory airflow obstruction.

With mechanical insufflation/exsufflation, a large increase in mean PCF was noted in the NMD group (76\%). A smaller but still significant increase of $9 \%$ was observed in the control group. Given that the control subjects were not flow-limited, the observed increase in PCF is in keeping with the expected increase in transpulmonary pressure caused by mechanical insufflation/exsufflation. However, it should be stated that this increase was small in magnitude, in contrast to that in patients with NMD, and does not suggest a clinical role for mechanical insufflation/exsufflation in patients with normal expiratory muscle strength. The value of insufflation/exsufflation in obstructive lung disease was not assessed in the present study. Previous work has assessed the changes induced by cough augmentation in adults [19, 20, 23-25]; however, few previous studies have carried out detailed physiological assessment of the effect of cough augmentation in both adults and children with the degree of respiratory muscle weakness observed in the present patient group. 

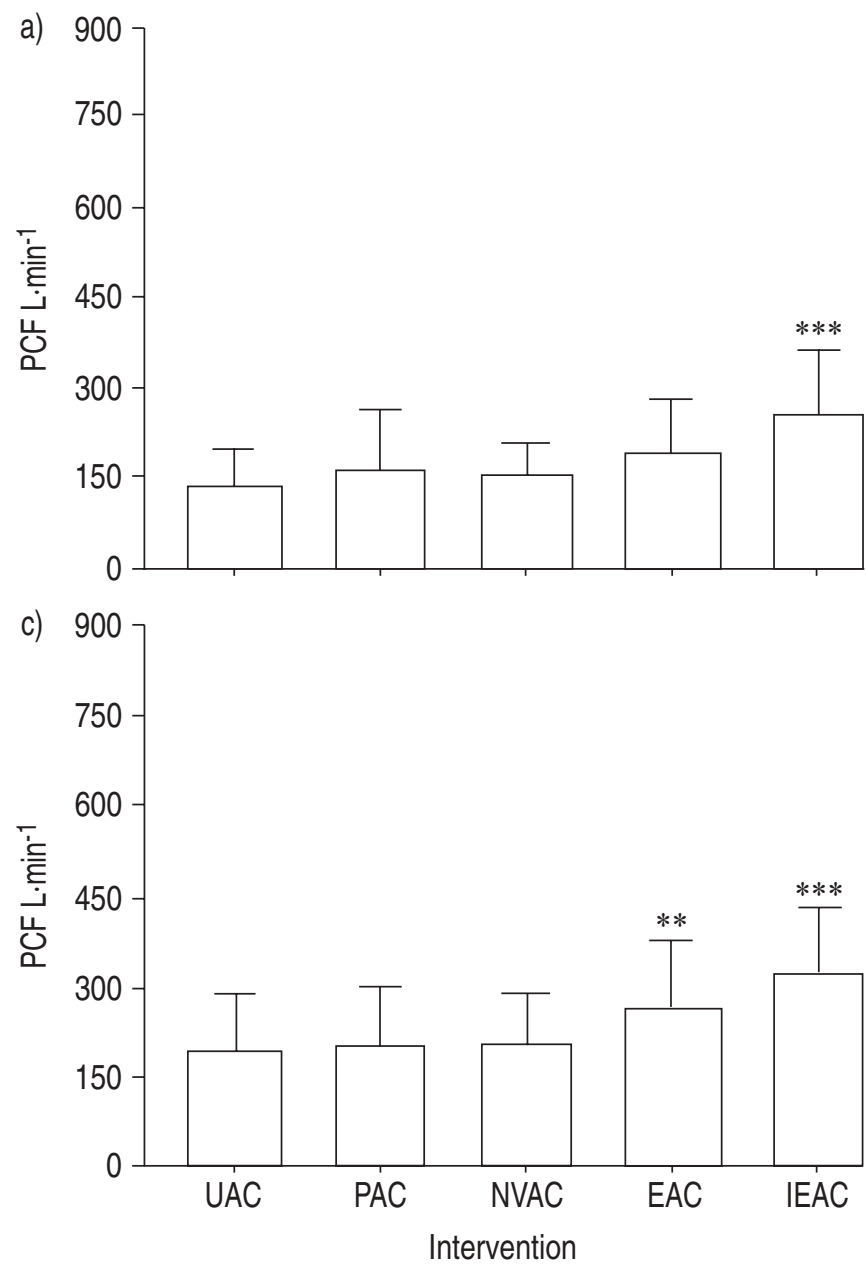

b)

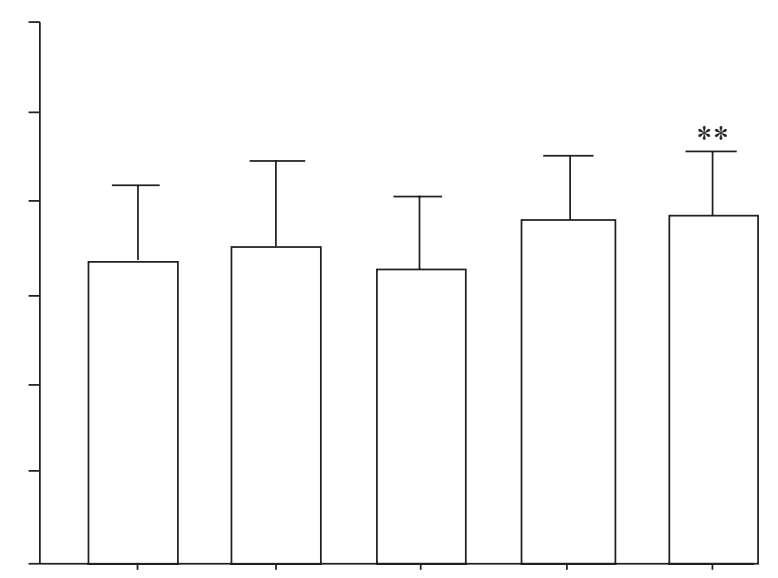

d)

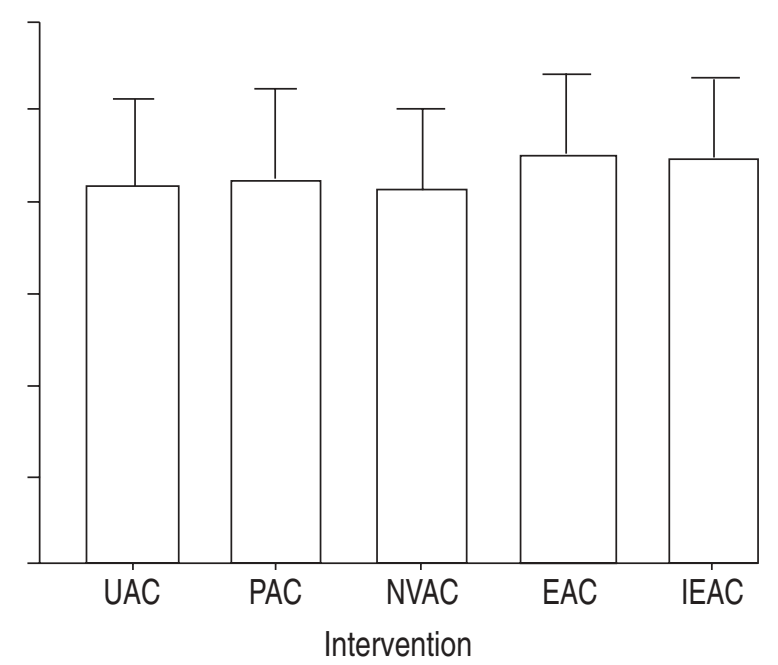

Fig. 2. - Peak cough flow (PCF) in a) paediatric patients, b) paediatric controls, c) adult patients, and d) adult controls. Data are presented as mean \pm SD. UAC: unassisted cough; PAC: physiotherapy-assisted cough; NVAC: noninvasive ventilator-assisted cough; EAC: exsufflation-assisted cough; IEAC: insufflation/exsufflation-assisted cough. ${ }^{* *}, * * *: \mathrm{p}<0.01, \mathrm{p}<0.001$ versus $\mathrm{UAC}$.

Cough is crucially important for adequate airway clearance. The present study examined the effect on PCF of a variety of interventions and showed that a combination of insufflation and exsufflation causes the greatest increase in PCF. An increase in inspiratory tidal volume is also desirable in mobilisation of secretions, as this enables the generation of higher peak expiratory flows. Patients with respiratory muscle weakness are often unable to generate the increased tidal volume required and repeated attempts to do so may fatigue the individual. To prevent exhaustion, the use of noninvasive ventilation, particularly during acute hypercapnic exacerbations, can provide an increase in tidal volume and therefore aid mobilisation of secretions. However, in the current study, this approach was less effective than mechanical insufflation/ exsufflation in increasing PCF.

SivASOTHY et al. [25] studied the effects of cough augmentation, including mechanical insufflation, in subjects with respiratory muscle weakness. The present work differs from their study in several respects. In their study, mechanical insufflation/exsufflation pressures were set at 20 and $-20 \mathrm{cmH}_{2} \mathrm{O}$, two insufflator/exsufflator cycles were used to aid inflation and deflation of the thorax and, after a third inspiration, the subject was asked to make a maximal voluntary cough without the aid of negative pressure. The coughs were, therefore, performed without the aid of exsufflation. The present authors found greater improvement in PCF with the combined insufflation/exsufflation-assisted cough than with insufflation alone. SIVASOTHY et al. [25] found that patients with scoliosis showed no increase in PCF and hypothesised that higher insufflation pressures may be required in this subgroup. In the present study, it was ensured that the pressure was titrated to patient comfort and, with this approach, it was possible to show significant benefit in patients with scoliosis. Like Sivasothy et al. [25], the present authors believe a pneumotachograph gives a more accurate measure of PCF than a standard peak flow meter.

A further notable observation in the present study was that, during titration of mechanical insufflation/exsufflation pressures to patient comfort, the highest insufflation and exsufflation pressures did not necessarily produce the greatest PCF. One reason for this discrepancy could be vocal cord dysfunction, either due to the disease (despite exclusion of patients with moderate or severe bulbar involvement) or as a result of upper airway collapse, secondary to the application of positive or negative pressure during insufflation or exsufflation, respectively [26].

BACH and coworkers [1, 23, 24] have previously suggested that a minimum assisted PCF of $160 \mathrm{~L} \cdot \mathrm{min}^{-1}$ is required to clear airway debris, where assistance consists of air stacking to maximal insufflation and an abdominal thrust at the time of coughing. Previous retrospective case series [1, 20, 23, 27] from the same group suggest that it may be possible to improve 
survival and reduce pulmonary morbidity and hospitalisation rate in patients with a PCF below this level, using noninvasive ventilation and mechanical insufflation/exsufflation, without resorting to tracheostomy. These retrospective data require confirmation in a controlled prospective study.

In conclusion, the present data confirm that a combination of insufflation and exsufflation increases peak cough flow in both children and adults with severe respiratory muscle weakness secondary to childhood-onset neuromuscular disease, in the absence of severe bulbar dysfunction. The use of mechanical insufflation/exsufflation is widespread in North America in subjects with neuromuscular disease. Several case series [1, 20, 23,27 ] suggest an important role for mechanical insufflation/ exsufflation in the prevention of respiratory morbidity in patients with neuromuscular disease. In the absence of prospective evidence, based upon well-designed randomised studies, there may remain considerable obstacles to the widespread adoption of this device within the UK and Europe. Therefore, randomised trials are now warranted, not only to assess whether regular use of an insufflator/exsufflator can reduce the long-term impact of chest infections in these patients but also to investigate whether the combination of insufflation and exsufflation during acute respiratory tract infections can improve clinical outcome more effectively than existing cough augmentation techniques.

\section{References}

1. Bach JR, Ishikawa Y, Kim H. Prevention of pulmonary morbidity for patients with Duchenne muscular dystrophy. Chest 1997; 112: 1024-1028.

2. Polkey MI, Lyall RA, Green M, Nigel Leigh P, Moxham J. Expiratory muscle function in amyotrophic lateral sclerosis. Am J Respir Crit Care Med 1998; 158: 734-741.

3. Carter GT, Abresch RT, Fowler WM, Johnson ER, Kilmer DD, McDonald CM. Profiles of neuromuscular disease. Spinal muscular atrophy. Am J Phys Med Rehabil 1995; 74: S150S159.

4. Bott J, Agent P. Physiotherapy and nursing during noninvasive positive pressure ventilation. In: Simonds AK, ed. Non-Invasive Respiratory Support: a Practical Handbook. London, Arnold, 2001; pp. 230-247.

5. McDonnell T, McNicholas WT, FitzGerald MX. Hypoxaemia during chest physiotherapy in patients with cystic fibrosis. Ir J Med Sci 1986; 155: 345-348.

6. Fauroux B, Boule M, Lofaso F, et al. Chest physiotherapy in cystic fibrosis: improved tolerance with nasal pressure support ventilation. Pediatrics 1999; 103: E32.

7. Heritier F, Rahm F, Pasche P, Fitting JW. Sniff nasal inspiratory pressure. A noninvasive assessment of inspiratory muscle strength. Am J Respir Crit Care Med 1994; 150: $1678-1683$.

8. Rafferty GF, Leech S, Knight L, Moxham J, Greenough A. Sniff nasal inspiratory pressure in children. Pediatr Pulmonol 2000; 29: 468-475.

9. Wilson SH, Cooke NT, Edwards RH, Spiro SG. Predicted normal values for maximal respiratory pressures in Caucasian adults and children. Thorax 1984; 39: 535-538.

10. Chetta A, Harris ML, Lyall R, et al. Whistle mouth pressure as a test of expiratory muscle strength. Eur Respir J 2001; 17: 688-695.

11. Uldry C, Fitting JW. Maximal values of sniff nasal inspiratory pressure in healthy subjects. Thorax 1995; 50: 371-375.

12. Black LF, Hyatt RE. Maximal respiratory pressures: normal values and relationship to age and sex. Am Rev Respir Dis 1969; 99: 696-702.

13. Laporta D, Grassino A. Assessment of transdiaphragmatic pressure in humans. J Appl Physiol 1985; 58: 1469-1476.

14. Quanjer PhH, Tammeling GJ, Cotes JE, Pedersen OF, Peslin R, Yernault JC. Lung volumes and forced ventilatory flows. Eur Respir J 1993; 6: Suppl. 16, 5-40.

15. Aitken RC. Measurement of feelings using visual analogue scales. Proc R Soc Med 1969; 62: 989-993.

16. Bach JR. Update and perspective on noninvasive respiratory muscle aids. Part 2: the expiratory aids. Chest 1994; 105: $1538-1544$.

17. Simonds AK, Muntoni F, Heather S, Fielding S. Impact of nasal ventilation on survival in hypercapnic Duchenne muscular dystrophy. Thorax 1998; 53: 949-952.

18. Meir-Jedrezejowicz A, Brophy C, Green M. Respiratory muscle weakness during upper respiratory tract infections. Am Rev Respir Dis 1988; 138: 5-7.

19. Bach JR, Saporito LR. Criteria for extubation and tracheostomy tube removal for patients with ventilatory failure. A different approach to weaning. Chest 1996; 110: $1566-1571$.

20. Bach JR. Amyotropic lateral sclerosis: prolongation of life by noninvasive respiratory aids. Chest 2002; 122: 92-98.

21. Kang SW, Bach JR. Maximum insufflation capacity. Chest 2000; 118: 61-65.

22. Polkey MI, Luo Y, Guleria R, Hamnegard CH, Green M, Moxham J. Functional magnetic stimulation of the abdominal muscles in humans. Am J Respir Crit Care Med 1999; 160: 513-522.

23. Bach JR. Amyotrophic lateral sclerosis: predictors for prolongation of life by noninvasive respiratory aids. Arch Phys Med Rehabil 1995; 76: 828-832.

24. Bach JR. Mechanical insufflation-exsufflation. Comparison of peak expiratory flows with manually assisted and unassisted coughing techniques. Chest 1993; 104: 1553-1562.

25. Sivasothy P, Brown L, Smith IE, Shneerson JM. Effect of manually assisted cough and mechanical insufflation on cough flow of normal subjects, patients with chronic obstructive pulmonary disease (COPD), and patients with respiratory muscle weakness. Thorax 2001; 56: 438-444.

26. Parreira VF, Jounieaux V, Aubert G, Dury M, Delguste PE, Rodenstein DO. Nasal two-level positive-pressure ventilation in normal subjects. Effects of the glottis and ventilation. Am J Respir Crit Care Med 1996; 153: 1616-1623.

27. Gomez-Merino E, Bach JR. Duchenne muscular dystrophy: prolongation of life by noninvasive ventilation and mechanically assisted coughing. Am J Phys Med Rehabil 2002; 81: $411-415$. 